\title{
What if? Strategy Design for Enacting Enterprise Performance
}

\author{
Simon Grand
}

\begin{abstract}
Strategy making is confronted with a flow of issues and challenges, simultaneously implying fundamental uncertainties and strategic opportunities for current and future enterprise performance. For entrepreneurial strategizing, it is important to successfully translate such issues and challenges into value-creating initiatives, businesses, solutions, and products. In this chapter, we argue that strategy design is essential under these conditions, because it allows proactive creation and realization of promising strategic opportunities, while at the same time establishing organizational pre-conditions for future opportunity creation and realization. Specifically, we identify 10 strategy design practices and show how they shape entrepreneurial strategizing and enterprise performance. Additionally, we identify specific steps to introducing such practices into the strategy process of an enterprise.
\end{abstract}

Keywords Strategy design - Entrepreneurial strategizing - Enterprise performance $\bullet$ Practices $\bullet$ Uncertainties

\section{Focus: Enacting Enterprise Performance}

Strategy making is confronted with a continuous flow of challenges, implying, at the same time, fundamental uncertainties and strategic opportunities (Quinn 1980; Burgelman 2002): for example, investing in novel knowledge domains and research areas, which might shape future innovation opportunities. Other challenges include: interpreting changing rules of the game in an industry, which might disrupt established value constellations, exploring the emergence of disruptive technologies, which outperform incumbent systems and solutions, or making sense of changes in current business models - as well as related shifts in pre-dominant modes of organizing and collaborating. Thus, an entrepreneurial approach to strategy making implies not only successfully enacting such opportunities and challenges, but always shaping the organizational pre-conditions for systematically seizing such opportunities and taking on such challenges as a company, in specific

\footnotetext{
S. Grand $(\bowtie)$

Institute for Systemic Management and Public Governance (IMP-HSG), University of

St.Gallen, Dufourstrasse 40a, 9000 St.Gallen, Switzerland

e-mail: simon.grand@unisg.ch
} 
situations over time. As Rei Kawakubo, the founder of the fashion label Comme des Garçons argues: "My work takes place where creating a company as a whole and creating clothes overlap. It cannot be one or the other" (Shimizu and NHK 2005). In an entrepreneurial perspective, creating and realizing opportunities and creating and advancing a company can only be understood as connected and mutually interdependent (Grand 2016, forthcoming).

We learn, then, from Peter F. Drucker, that the best way to predict the future is to create it. Creating the future is characterized by a series of challenges; it implies dealing with the inherent uncertainty embodied in any attempt to deal with the future. It also implies imagining novelties, which go beyond the taken-for-granted, to envision alternative futures. It implies making possible what is not possible today, thus enriching and enlarging the entrepreneurial action space. This also implies an exploration of what should be, having a normative dimension: how desirable, relevant, valuable is the future we build? It is only by explicitly considering these challenges that we can understand why Joseph A. Schumpeter describes entrepreneurial practice as "creative destruction" (Schumpeter 1942): it implies critical challenge, proactive transformation and creative transcendence of the present, taken-for-granted, self-evident-whether it is a known product, an established technology, a known business model, a routinized organizational structure or unquestioned management practices.

Entrepreneurial strategy making is thus creative action, the proactive enactment of the world as it is, "... to create worlds as they could be" (Simon 1996, p. 4). The central question in entrepreneurial practice is: what if? ... what if it would be possible to use our mobile phones as multimedia and entertainment devices; ... what if it would be possible to access valuable information and expert knowledge for free; ... what if it would be possible to systematically cure cancer; ... what if our current products would be out of the market in one year; ... what if societal value creation becomes as central for enterprise performance as financial success. Interestingly, this is also a guiding focus in design practice: "The impossible drives the possible. A designer's motto should always be: what if?" (Lukic and Katz 2011, p. XXIX), identified as an essential focus in any creative design process (Dunne and Raby 2013). The present chapter argues that we gain relevant insights for entrepreneurial strategizing from a design perspective, which allows creative and robust answers to the question: what if?

\section{Approach: Ten Practices of Strategy Design}

\section{Relating Strategy and Design}

Understanding entrepreneurial practices as strategy design requires opening the black boxes of "strategy" and "design". By strategy, we understand not primarily what executives say, state and plan as their so-called strategy, but what 
organizations actually do (Mintzberg and Waters 1985); in other words, strategy in our view is best identified with the actual action patterns characterizing "... how an organization moves forward" (Rumelt 2011 p. 6). This also implies identifying strategy as the realized strategy of the company and its management (Bower and Gilbert 2005). By design, we understand not primarily the creation of visual and material artifacts, but the practices and processes necessary to create, establish, enact and sustain such visual, discursive and material artifacts and actions as materializations of possible, potential worlds (Bleecker 2009; Auger 2010; Dunne and Raby 2013). This requires considering strategy making primarily as creative action (Joas 1992). We identify the 10 core practices essential for entrepreneurial strategizing "in the making": these practices, through their interplay, ensure enterprise performance under conditions characterized by fundamental uncertainty.

The practices are identified through our empirical research on strategy processes in various industry and technology contexts, including software engineering, information technology, pharma and life sciences, engineering, robotics and artificial intelligence, as well as fashion and design in the context of our RISE Management Innovation Lab [www.rise.ch; see also Grand (2016)]. Furthermore, our argument is strengthened by our research on creative economies and creative enterprises in partnership with the Zurich University of the Arts, as well as various collaborations with artists and designers, exploring their creation and realization practices, methods and tools [www.creativeeconomies.com; see also Grand and Jonas (2012)]. The 10 practices of strategy design are also inspired by our innovation partnerships with various companies, mobilizing the practices and developing them into their own repertoires of strategy making. They are also tested in our own entrepreneurial engagements, to explore them from "inside".

\section{Practice 01: Projecting}

From our perspective, entrepreneurial strategizing is not primarily an analytical process: under uncertainty, we are not able to develop a clearer perspective by adding more information, analyzing more data or systematically exploring the world as it is (March 1994; Shapira 1995). Rather, it is important to imagine, launch and formulate desirable, valuable, attractive and relevant futures, as they could be, in the form of questions, hypotheses, propositions, and simulations: for example the question Winy Maas from the architectural practice MVRDV asks in one of his projects: how would a city have to be built to allow anyone to get from any place to any other place within less than 5 minutes? (Maas 2003). Similarly, we find such projection in the business world, very prominently in the proposition Apple has formulated decades ago, leading to the Macintosh: we build a computer that is easy to use, of high quality, affordable and beautiful (Kawasaki 2000). Such questions, propositions and hypotheses make a substantial leap forward and open action spaces for the creation and realization of entrepreneurial opportunities. At the same time, they transcend and critically reflect the present we know. 
Entrepreneurial strategizing asks "What if?" and systematically develops proposals to answer the question in novel, inspiring and attractive ways.

\section{Practice 02: Prototyping}

Prototyping is another important practice to project attractive future possibilities. It is important to make proposals as tangible as possible, not sticking with the general idea or broad image, but concretizing them in the form of specific concepts, material prototypes and precise stories. We know from design practice how important specific materializations are, because they substantially influence what is possible and what is not (Gänshirt 2007). In the context of entrepreneurial strategizing, we observe that different materializations also matter: strategy making by drawing a business model on paper is different from simulating a strategy by trying out its consequences for the future website of a company, by putting together a simplified material artifact of a potential future product in a bricolage process, or by explaining the value proposition of the enterprise in an elevator pitch. Most often, specific media like PowerPoint are used without further consideration to developing and specifying a strategy. However, this always introduces specific technical features and media-specific qualities into the process (Tufte 2003; Orlikowski and Yates 1994; Kaplan 2011). Obviously, strategy design through prototyping implies reflecting the current strategy process and the usage of media, stories and artifacts, as well as identifying the most productive media for prototyping, thus materializing strategic ideas and novel concepts.

Entrepreneurial strategizing explores the potential of specific media for prototyping strategic ideas, proposals and stories.

\section{Practice 03: Evaluating}

Whatever strategic ideas and stories are proposed and prototypically explored, it is essential to be explicit about specific criteria, which will evaluate the strategic relevance of such ideas and stories: what are the predominant expectations concerning growth potential, radical novelty, distinctive features, financial success, social relevance and how are they evaluated in the strategy process? (Rüegg-Stürm and Grand 2015). We learn from design practice how important it is to translate and operationalize often intuitive, subjective judgment into robust evaluations. These can systematically be applied to proposed ideas and concepts, stories and prototypes, then communicated and justified as an enterprise-specific reference system or performance model (Grand and Bartl 2011). Entrepreneurial strategizing poses the challenge of deciding whether it is possible to quantify certain dimensions in terms of numbers and metrics, and how they are combined with qualitative evaluation dimensions including aesthetic or societal aspects. How elegant is a new 
business model; or how normatively valid is a new product; or how successful is an existing product? Exploring different types of judgment devices, including operating figures, rankings, benchmarks, expert opinions, references to experience and subjective judgment is thus essential for entrepreneurial strategizing.

Entrepreneurial strategizing systematically mobilizes various judgment devices for translating subjective judgments into justified evaluations.

\section{Practice 04: Experimenting}

It is one thing to build prototypes for exploring the potential of promising ideas and fascinating concepts; it is another to systematically experiment with testing such ideas, concepts, stories and prototypes. While experimenting is often associated with informal trying-out, we learn from research on scientific experimentation and design processes how important it is to introduce a systematic structure into the experimentation process (Brown 2009). This is guided by asking a set of questions: what exactly are the questions asked and how far do specific prototypes answer those questions? How exactly are experiments evaluated? How are experiments tracked by the usage of inscription systems, allowing reconstruction of experimental events? How systematic is the confrontation of a new prototype with actual and potential user communities? How explicit is the application of particular test criteria tracked before taking decisions and prioritizing options? How do experiments build on each other to allow for creative variation and serial validation (Knorr Cetina 1981, 1999)? Experimenting does require laboratories as experimental systems (Rheinberger 1997), which frame, structure, equip, protect, track and document experiments, making them traceable and accessible (Latour 2004).

Entrepreneurial strategizing requires experimental systems, which allow systematically testing of novel concepts and prototypes.

\section{Practice 05: Routinizing}

It is one kind of challenge to imagine attractive opportunities, develop convincing prototypes and systematically evaluate and test them, and another to develop the organizational context, which systematically enables and fosters the creation of novel, inspiring and attractive opportunities. It is thus essential, in entrepreneurial strategizing, to translate new insights, concepts, perspectives and experiences into organizational knowledge, expertise and practices, as well as enacting them systematically, so that they become organizational routines. Furthermore, it is important to routinize such creation processes themselves (Grand 2016). Interestingly, successful design enterprises are often characterized by highly routinized creation processes (Hargadon and Sutton 1997; Salvato 2003, 2009). To ensure enterprise performance in this perspective requires systematic routinization, which allows 
recurrent translation of novel ideas, concepts and proposals into successful products, solutions and technologies. To sustain enterprise performance implies going through this process not only once, but in a recurrent mode. This can also be identified as the dynamic capabilities of an enterprise (Eisenhardt and Martin 2000), which go beyond the competence to create, by embedding creation into organizational action and strategy making (Floyd and Wooldridge 2000).

Entrepreneurial strategizing engages for the systematic, enterprise-specific routinization of creative concepts and the creative process itself.

\section{Practice 06: Mobilizing}

Materializing, experimenting and routinizing are very costly processes; typically, they lead to many variations that do not work, do not survive a disciplined evaluation process and cannot be realized within a reasonable time frame. As a consequence, entrepreneurial strategizing continuously engages in the mobilization of relevant resources to make such processes possible. Resource mobilization implies diverse resources as: financial resources allowing for strategic investment (Burgelman 2002), customer insights exploring the actual and potential relevance of any new concept (Brown 2009), relevant expertise in various competence fields etc. It is important to explore to what extent external parties must be mobilized in relevant ways and to what extent internal capabilities and related processes can be established, to ensure that the translation of promising ideas, concepts and perspectives really takes place (Murtha et al. 2001). Resources are, therefore, not simply tangible and intangible assets; they provide potential to act, opening up entrepreneurial action spaces for the creation of novel products, solutions and businesses (Rüegg-Stürm and Grand 2015).

Entrepreneurial strategizing systematically attracts relevant resources, while engaging in their creation and allocation, to enlarge the action space.

\section{Practice 07: Realizing}

Whatever is created, imagined and developed gains impact through its successful translation into a relevant product, an attractive service, or a working business model. It is essential for entrepreneurial strategizing to focus on actual value creation and return appropriation from initial ideas, prototypical artifacts and interesting stories. We learn from design practice that this translation is in itself a highly creative process, which potentially transforms the entire concept or project again. This implies that we understand the transition from prototypical concepts into working products as a highly creative and transformative practice, which substantially influences the actual success and enterprise performance. Through systematic routinization over time, the alignment and productive interaction 
between projecting, prototyping and experimenting — on one hand and evaluation, structuring and realization on the other-can be intensified and further strengthened. Entrepreneurial strategizing thus substantially relies on the establishment of dynamic interfaces, interaction processes and communicative platforms relating different strategy design practices, recognizing the creative potential in all of them.

Entrepreneurial strategizing systematically concentrates on the translation of concepts, ideas, stories and prototypes into actual outcomes.

\section{Practice 08: Connecting}

Whatever emerges from entrepreneurial strategizing, both in terms of specific products and services, but also of organizational action patterns and moves, essentially depends on how it is connected to relevant contexts and environments. How are current customer expectations met or challenged, how are products connected to stories that make sense, how are external parties and communities mobilized for the successful translation of novel products and services into actual usage and conviction? Connecting like this is a continuous activity for entrepreneurial strategizing, with an impact on strategy design practices, for example ... evaluating: what are important criteria, dimensions and related judgment devices in the eyes of relevant customers and communities (Bower and Gilbert 2005); . . . or mobilizing: how can relevant environments and actors be mobilized as resources for the value creation and strategic advancement of the organization, thus contributing to the creation, enlargement and ensuring of entrepreneurial performance now and in the future; ... or realizing: how can a robust network of strategic partnerships be ensured over time (Dyer and Singh 1998). Connecting is a highly creative process; not just a simple transfer from one context to another, but a highly creative translation process as well (Callon 1986; Latour 2005).

Entrepreneurial strategizing systematically connects organizational activities to relevant contexts, while proactively enacting the resulting interfaces.

\section{Practice 09: Scaling}

Business impact and enterprise performance do not automatically result from creation and innovation. It requires continuous scaling of the highly situated activities involved in entrepreneurial strategizing (Thévenot 2006; Grand 2016): proposing a new concept, exploring a new prototype, applying a judgment device, interacting with an investor, propagating a new product through attractive stories are always highly situated activities. However, at the same time, creation and innovation have the potential to shape organizational outcomes and enterprise performance: how an organization moves forward. As a consequence, entrepreneurial strategizing constantly attempts to explore potential for any activity and 
practice beyond the situation, to shape other situations and interactions, but also to amplify the impact across space and time. This explains the importance of entrepreneurial engagement for proactively establishing new possibilities and opportunities, at the same time mobilizing relevant resources and connections. Furthermore, it explains the importance of standardization, formalization, structuring and routinization for entrepreneurial strategizing (Grand and Ackeret 2012); only these processes allow transcendence of situatedness, localness and fragility of strategizing activities and interactions towards distinctive, sustainable and competitive performance.

Entrepreneurial strategizing proactively interprets situated interactions as possibilities to leverage local activities for global impact.

\section{Practice 10: Curating}

Overall, the different strategy design practices discussed so far are individually relevant. At the same time, they work only in relation to other practices and their continuous enactment. We learn from the creative economies that continuous interaction cannot be managed or governed in a linear and directive sense (Boland and Collopy 2004). It must be curated by playing with existing dynamics and connecting unconnected processes, remaining open to both unexpected events and incidences, (which turn into promising possibilities for new interpretations of individual practices), but also to ways of advancing their interactions, interfaces and complementarities in novel directions (Grand and Weckerle 2014). "There is a fundamental similarity within the act of curating, which, at its most basic, implies connecting cultures, bringing their elements into proximity with each other-the task of curating is to make junctions, to allow different elements to touch" (Obrist 2014 , p. 1). For realizing such novel connections, it is often essential to work toward alternative institutionalizations by building enterprises to provide the context for successfully moving forward.

Entrepreneurial strategizing requires curating both of situated events, actions and initiatives, as well as of their interactions, connections and scaling.

\section{Conclusion: Exploring Strategy Design Practices}

Obviously, strategy design is straightforward, but also implies challenges. As a consequence, it is essential not to approach strategy design in its entirety as a complex, distant, abstract concept, but to start with one specific practice after the other, while at the same time carefully curating the overall interaction and interplay with established practices. Specifically, we suggest the following starting points for exploring strategy design practices: 
Practice 01: Projecting: Ask "What if?" and develop proposals to answer the question in novel, inspiring and attractive ways.

Strategy making is often characterized by the implicit assumption that the past can be used as a good reference for extrapolating the future. Asking "What if?" in a strategy workshop is a good way of challenging such taken-for-granted continuity: ... what if our most successful product would have to be sold at half price ... what if our most important customers were located in a different part of the world than they are today ... what if it would be possible to completely automate our manufacturing process ... what if our customer interaction would be completely digital. It is important, in strategy design perspective, not only to formulate such questions and explore their potential, but to actually develop prototypes of resulting products, interfaces or marketing campaigns (Practice 02: Prototyping), as well as defining the experimental system necessary to test them systematically (Practice 04: Experimenting).

Practice 03: Evaluating: Entrepreneurial strategizing systematically mobilizes various devices for translating subjective judgments into justified evaluations.

Strategy making is often characterized by just a few explicit, quantified, typically financial measures of business success and entrepreneurial performance. At the same time, we observe in many strategy workshops and management meetings how important subjective judgments, feelings and intuitions are for evaluating novel ideas, surprising events or unexpected developments. Specifically discussing evaluation criteria and related judgment devices is a good way of making evaluation in entrepreneurial strategizing more explicit and appropriate for creation and innovation processes. It makes sense to identify how the pre-dominant evaluation criteria relate to the expectations of the most important strategic enterprise partners (lead users, major investors, technology providers, ...) (Practice 06: Mobilizing), as well as to the most important aspects that drive a successful realization and commercialization of a new initiative (Practice 07: Realizing).

Practice 08: Connecting: Entrepreneurial strategizing connects organizational activities to relevant contexts, while proactively enacting the resulting interfaces.

Strategy making is often seen as a specialized executive management activity, without consideration of how other actors, either in or outside the enterprise, can be mobilized for entrepreneurial strategizing. As a consequence, involving novel perspectives and relevant actors, (typically not involved in strategy making) can substantially strengthen the process. Strategy making is often seen as irrelevant to the overall organization; systematically communicating about strategic issues, ideas and initiatives, (thus elaborating convincing modes, media and platforms for communication) can make a substantial difference. Opening up strategy making in these two directions also allows more systematic anchoring of novel perspectives into organizational capabilities, practices and routines (Practice 05: Routinizing), thus leveraging them systematically across situations, activities and initiatives (Practice 09: Scaling).

The fundamental guiding principle for entrepreneurial strategizing is that strategy design always occurs while both creating a company as a whole and creating novel products, solutions, stories and businesses, not just one or the other. 


\section{References}

Auger J (2010) Alternative presents and speculative futures. In: Swiss Design Network (ed) Negotiating futures-design fiction. HGK Basel, Basel, pp 42-57

Bleecker J (2009) Design fiction: from props to prototypes. In: Swiss Design Network (ed) Negotiating futures-design fiction. HGK Basel, Basel, pp 58-67

Boland RJ, Collopy F (2004) Managing as designing. Stanford Business Books, Stanford, CA

Bower JL, Gilbert CG (2005) From resource allocation to strategy. Oxford University Press, Oxford Brown T (2009) Change by design. Harper Business, New York

Burgelman RA (2002) Strategy is destiny: how strategy-making shapes a company's future. Free Press, New York

Callon M (1986) Some elements of a sociology of translation: domestication of the scallops and the fishermen of St. Brieuc Bay. In: Law J (ed) Power, action and belief: a new sociology of knowledge? Routledge, London, pp 196-229

Dunne A, Raby F (2013) Speculative everything: design, fiction, and social dreaming. MIT Press, Cambridge, MA

Dyer JH, Singh H (1998) The relational view: cooperative strategy and sources of interorganizational competitive advantage. Acad Manage Rev 23(4):660-679

Eisenhardt KM, Martin JA (2000) Dynamic capabilities: what are they? Strateg Manag J 21(10/11):1105-1121

Floyd SW, Wooldridge B (2000) Building strategy from the middle: reconceptualizing strategy process. Sage, London

Gänshirt C (2007) Werkzeuge für Ideen: Einführung ins Architektonische Entwerfen. Birkhäuser Verlag, Basel

Grand S (2016) Routines, strategies and management: engaging for recurrent creation 'at the edge'. Edward Elgar, Cheltenham

Grand S, Ackeret A (2012) Management knowledge: a process view. In: Schultz M, Maguire S, Langley A, Tsoukas $\mathrm{H}$ (eds) Constructing identity in and around organizations. Oxford University Press, Oxford, pp 261-305

Grand S, Bartl D (2011) Executive Management in der Praxis: Entwicklung-DurchsetzungAnwendung. Campus Verlag, Frankfurt am Main

Grand S, Jonas W (2012) Mapping design research. Birkhäuser Verlag, Basel

Grand S, Weckerle C (2014) Global creative systems, curatorial strategies. Working paper. www. creativeeconomy.ch. Accessed 27 Feb 2015

Hargadon A, Sutton RI (1997) Technology brokering and innovation in a product development firm. Adm Sci Q 42(4):716-749

Joas H (1992) Die Kreativität des Handelns. Suhrkamp Verlag, Frankfurt am Main

Kaplan S (2011) Strategy and PowerPoint: an inquiry into the epistemic culture and machinery of strategy making. Organ Sci 22(2):320-346

Kawasaki G (2000) Rules for revolutionaries: the capitalist manifesto for creating and marketing new products and services. Harper Business, New York

Knorr Cetina K (1981) The manufacture of knowledge: an essay on the constructivist and contextual nature of science. Pergamon Press, Oxford

Knorr Cetina K (1999) Epistemic cultures: how the sciences make knowledge. Harvard University Press, Cambridge, MA

Latour B (2004) Von "Tatsachen" zu "Sachverhalten": Wie sollen die neuen kollektiven Experimente protokolliert werden? In: Schmidgen H, Geimer P, Diering S (eds) Kultur im Experiment. Kulturverlag Kadmos, Berlin

Latour B (2005) Reassembling the social: an introduction to actor-network-theory. Oxford University Press, Oxford

Lukic B, Katz BM (2011) Nonobject. MIT Press, Cambridge, MA

Maas W (2003) Five minutes city. Episode Publishers, Rotterdam

March JG (1994) A primer on decision making: how decisions happen. Free Press, New York 
Mintzberg H, Waters J (1985) Of strategies, deliberate and emergent. Strateg Manag J 6(3): $257-272$

Murtha TP, Lenway SA, Hart JA (2001) Managing new industry creation. Stanford University Press, Stanford, CA

Obrist HU (2014) Ways of curating. Penguin, London

Orlikowski WJ, Yates J (1994) Genre repertoire: the structuring of communicative practices in organizations. Adm Sci Q 39(4):541-574

Quinn JB (1980) Strategies for change: logical incrementalism. Irwin, Homewood, IL

Rheinberger HJ (1997) Toward a history of epistemic things: synthesizing proteins in the test tube. Stanford University Press, Stanford, CA

Rüegg-Stürm J, Grand S (2015) The St. Gallen management model. Haupt, Bern

Rumelt R (2011) Good strategy/bad strategy: the difference and why it matters. Profile Books, London

Salvato C (2003) The role of micro-strategies in the engineering of firm evolution. J Manag Stud 40(1):83-108

Salvato C (2009) Capabilities unveiled: the role of ordinary activities in the evolution of product development processes. Organ Sci 20(2):384-409

Schumpeter JA (1942) Capitalism, socialism and freedom. Harper and Brothers, New York

Shapira Z (1995) Risk taking: a managerial perspective. Russell Sage, New York

Shimizu S, NHK (2005) Unlimited: Comme des Garçons. Heibonsha, Tokyo

Simon HA (1996) The sciences of the artificial, 3rd edn. MIT Press, Cambridge, MA

Thévenot L (2006) L'action au pluriel. Sociologie des régimes d'engagement. Editions La Découverte, Paris

Tufte ER (2003) The cognitive style of PowerPoint. Graphics Press, Cheshire, CT 